\title{
ENSINAR E APRENDER INGLÊS E A DESCENTRALIZAÇÃO DO FALANTE NATIVO
}

\author{
ENSEÑAR Y APRENDER INGLÊS Y LA DESCENTRALIZATIÓN DEL HABLANTE \\ NATIVO
}

\author{
TEACHING AND LEARNING ENGLISH AND THE NATIVE SPEAKER \\ DECENTRALIZATION
}

\author{
Flávius Almeida dos ANJOS ${ }^{1}$
}

RESUMO: Este artigo é uma breve reflexão sobre o ensino e a aprendizagem da língua inglesa. Destaca a presença e a relevância de se aprender esse idioma hoje, para participar de diversas ações que são engendradas através dessa língua. À luz da Linguística Aplicada, coloca em xeque a figura mítica do falante nativo e sugere a sua descentralização no contexto de aprendizagem da língua inglesa, com o intuito de legitimar os novos falantes desse idioma global. Para aquecer a reflexão, toma-se como base a noção do status de língua franca global que o inglês alcança na contemporaneidade, e, desse modo, para uma melhor implementação desse processo, este artigo discute questões fundamentais, tais como identidade, ideologia, falante nativo e não nativo. A reflexão converge para o fato de que é preciso romper com os padrões hegemônicos, porque essa abordagem está ultrapassada, e aprender a ensinar um inglês mais local.

PALAVRAS-CHAVE: Ensinar. Aprender. Língua inglesa. Falante. Descentralização.

RESUMEM: Este artículo és una breve reflexión acerca de la enseñanza y el aprendizaje del inglés. Él destaca la presencia y la relevancia de se aprender este idioma hoy, para participar de diversas acciones que son engendradas através de esa lengua. A la luz de la Linguistica Aplicada, él pone en jaque la figura mítica de lo hablante nativo y sugiere su descentralización en lo contexto de aprendizaje del inglés, con la intención de legitimar los nuevos hablantes de ese idioma global. Para calentar la reflexión, se toma como base la noción del estatus de lengua franca global que el inglés alcanza en la contemporaneidad, y, de ese modo, para una mejor implementación de ese proceso, este artículo discute cuestiones fundamentales, tales como identidad, ideología, hablante nativo e no nativo. La reflexión converge para el hecho de que és necesario romper con los patrones hegemónicos, porque este enfoque está sobrepasado, y aprender como enseñar uno inglés más global.

PALABRAS CLAVE: Enseñar. Aprender. Lengua inglesa. Hablante. Descentralización.

ABSTRACT: This paper is a brief reflection about the teaching and learning of English. It highlights the presence and relevance of learning this language nowadays, to take part in

${ }^{1}$ Universidade Federal do Recôncavo da Bahia (UFRB), Centro de Cultura, Linguagens e Tecnologias Aplicadas (CECULT), Santo Amaro da Purificação - BA - Brasil. Professor Adjunto de língua inglesa. ORCID <https://orcid.org/0000-0001-9918-7693>. E-mail: flaviusanjos@ gmail.com 
several actions which are engendered through this language. Under the light of Applied Linguistic, it puts in check the native speaker as mythical creature and suggests its decentralization in the English language context, aiming at legitimizing the new speaker of this global language. To warm this reflection, it takes as base the global lingua franca status that English achieves in the contemporaneity, and therefore, for a better implementation of this process, this paper discusses fundamental issues, such as identity, ideology, native and nonnative speaker. This reflection converges to the fact that it is necessary to break with hegemonic patterns, because this approach is outdated, and to learn to teach a more local English.

KEYWORDS: Teaching. Learning. English language. Speaker. Decentralization.

\section{Introdução}

É incontestável a presença da língua inglesa em diversos cenários locais e a necessidade da sua aprendizagem para participação em muitas ações que estão diariamente sendo engendradas nessa língua. Esse idioma desterritorializado, que já escapou das mãos dos ingleses, dos norte-americanos, dos australianos, dos novo-zelandeses e todos que acreditavam ter propriedade sobre ele (RAJAGOPALAN, 2014), tem afetado profundamente a vida das pessoas em diversas partes do mundo. Para Crystal (2012), para onde quer que se viaje, há placas e anúncios em inglês. Já Cogo (2012) pontua que os encontros em inglês como língua franca, podem ocorrer na internet, no Facebook, num escritório em Beijing, numa palestra universitária, em Amsterdam, numa barraca de mercado, em Marrakesh, num bar em Milão e em um abrigo em São Paulo. Assim, a imprescindibilidade da compreensão e uso dessa língua, em diversos ramos da vida em sociedade, aponta a necessidade da aprendizagem desse idioma. Entretanto, muitos contextos têm fomentado a aprendizagem dessa língua com base na figura do falante nativo, sem considerar as consequências de tal orientação.

O título deste artigo imediatamente sugere, de algum modo, benefício aos aprendizes de língua inglesa, ao colocar em pauta a descentralização do falante nativo de língua inglesa. Embora muitas instituições, ainda hoje, propaguem a figura do falante nativo como meio para atrair alunos, mal sabem sobre as consequências desse marketing em sala de aula e desconsideram, sobretudo, o status que a língua inglesa alcança nesse momento e as implicações que advêm disso. 


\section{A (des)centralização do falante nativo da língua inglesa}

A figura do falante nativo tem sido "vendida" como o modelo ideal, especialmente as versões hegemônicas norte Americana e a Britânica, que devem ser seguidas, imitadas, sob pena de não se falar bem o inglês. Desse modo, ecoa em muitos contextos a noção de que é preciso falar como um nativo, incluindo em suas práticas pedagógicas sentenças do tipo "I'll speak English just like an american". Há nessa empreitada uma ideologia macabra, que ao nortear os programas de ensino da língua inglesa, traz consequências que fazem os alunos se sentirem diminuídos em suas autoestimas, convergindo para o desenvolvimento de um sério complexo de inferioridade, ao serem confrontados com a figura mítica do falante nativo (RAJAGOPALAN, 2003). Assim, as consequências que advêm da adoção dessa abordagem se materializam em uma espécie de barreira psicológica, que dificulta a aprendizagem, tais como medo de errar, sentimento de inadequação e inferioridade. Como se vê, a escolha de uma abordagem centrada exclusivamente na figura do falante nativo pode atingir diretamente o aprendiz, lhe causando desconforto e outros sentimentos em relação ao uso da língua inglesa. Sobre isso é possível, encontrar na literatura contemporânea relatos de aprendizes de língua inglesa, tais como Barcelos (1995) e Anjos (2019), cuja abordagem de ensino, a qual foram submetidos, gerou sentimentos constrangedores, muito semelhante ao que Bernat (2009) definiu como a síndrome do impostor, uma espécie de constructo psicológico de sentimentos de inadequação, inautenticidade e fraudulência pessoal, pelo fato de não terem conseguido se igualar ao falante nativo das culturas hegemônicas que lhes foram impostas. Entretanto, é bom que se ressalte, que ambos também relatam que conseguiram se livrar desses sentimentos negativos, que impediam a comunicação em língua inglesa, ao perceberem que podiam manter as suas identidades, sem precisar emular o falante nativo.

Obviamente que isso converge com o fato de o inglês alcançar o status de língua franca global. Isto é, uma língua usada em larga escala, comum entre pessoas que não compartilham uma mesma base cultural (JENKINS, 2007). Na prática o que se tem observado é que são pessoas de diferentes nacionalidades que têm escolhido, cada vez mais, o inglês como alternativa de comunicação. Todavia, apesar do fenômeno crescente de uso do inglês como língua franca, prevalece o ensino da língua inglesa com orientação de base nativa, cuja correção e apropriação orientam-se pelo falante nativo (JENKINS, 2012). Muitos contextos de aprendizagem de língua inglesa fomentam a noção de que os aprendizes precisam alcançar o padrão dos falantes de inglês como primeira língua e, assim, mesmo sem saber, os aprendizes sofrem um exame comparativo constrangedor. Por isso mesmo trata-se de uma pedagogia 
inapropriada para aprender inglês. Mas o encantamento pela versão padrão (Received Pronunciation), tem respaldo e está presente ainda hoje em muitos contextos. Sobre isso, Jenkins (2009, p. 11, tradução minha) alerta que:

A "fascinação" pelo received pronunciation continua até hoje, e o sotaque continua a ser desejado mesmo em contextos de inglês como língua franca, onde muito da comunicação não envolve os nativos do inglês. Materiais para aprendizes de inglês, especialmente na Europa, mas também em outras partes da Ásia e da América Latina ainda promovem o received pronunciation como sendo superior. De fato, é frequentemente o único sotaque apresentado como modelo para produção, mesmo se outros sotaques nativos e ocasionalmente sotaques não nativos possam ser apresentados para propósitos de treinamento receptivos.

O que Jenkins coloca é muito mais complexo do que se possa imaginar, e uma das questões que emerge nesse cenário é a identidade do aprendiz/usuário/falante do inglês. Quando menciono no início deste artigo que muitas instituições, que ofertam a aprendizagem da língua inglesa, com foco no não-nativo, ignoram o status global dessa língua e as consequências que advêm disso, chamo atenção para a manutenção da identidade do aprendiz, que pode, frente a esse status, falar a língua inglesa do locus da sua própria identidade. Isso possibilita ressignificar, recriar essa língua em diferentes níveis. Nesse sentido é que mundo afora diversos povos têm dado um toque pessoal a essa língua e, por isso, já se fala em termos de variantes, como o inglês Indiano (Inglish), o inglês Chinês (Chinglish), o inglês Japonês (Japlish) e por que não o Brazilian English? Todas essas variantes se diferenciam em diversos aspectos dos padrões hegemônicos e com um toque idiossincrático têm respondido bem às demandas de comunicação locais.

Essa expansão e modificação da língua inglesa têm ocorrido por que ela se desatrelou das suas origens, tornando-se, desse modo, uma língua sem donos, sem tutelas; deixou de ser propriedade dessa ou daquela nação, desse ou daquele país (RAJAGOPALAN, 2009). Assim, por exemplo, frente à expansão da língua inglesa, conclui-se que não há um único sotaque nativo de referência para todos aqueles que estudam e ensinam inglês, o que também implica dizer que não há uma forma certa ou errada de pronunciar, considerando a diversidade de contextos onde o inglês é falado (ROCHA LIMA, 2009). Nesse sentido, é que Jenkins (2007) ressalta a importância de fazermos esforços mútuos para entendermos uns aos outros. Isso é o que importa. Que as pessoas se comuniquem. Assim, o sotaque não deve ser parâmetro para medir se alguém fala bem ou não uma determinada língua. O que é preciso observar são as noções por detrás da inferiorização dos sotaques. Quanto a isso, é preciso entender que, muitas vezes, a estigmatização de um sotaque não se dá apenas com base nele mesmo, mas trata-se de 
preconceito social, de classe. Nessa linha de raciocínio é que Fairclough (1998) chama atenção para o fato de que o inglês padrão, em todas as suas nuances, sempre foi visto como correto, e os outros não. Entretanto, para ele, isto estava diretamente relacionado com os estilos de vida e moralidade dos falantes e quando se tratava da classe trabalhadora, o inglês desses falantes era sempre visto como vulgar, lento, baixo, bárbaro etc.

Por isso tenho alertado para o fato de que é preciso romper com os padrões hegemônicos, porque acredito que essa abordagem está ultrapassada, e aprender a ensinar um inglês mais local. Para tanto, é preciso compreender que a ascensão do inglês como língua global impacta profundamente a pedagogia para ensinar esse idioma, que por ter a credencial de língua global, pode e deve ser ressignificado em perspectivas cada vez mais locais. Nesse sentido, é preciso que os professores estejam cientes desse status e que, embora, as culturas hegemônicas possam eventualmente servir também como referência, não devem, entretanto, ser as únicas. Além disso, as novas construções linguísticas, com base em perspectivas locais, precisam ser respeitas e, quem sabe, legitimadas, já que o próprio status dessa língua credencia não apenas a manutenção das identidades dos usuários, mas a ressignificação dessa língua, com toques locais.

\section{Considerações finais}

Se por um lado temos a consciência das forças que operam por detrás da língua inglesa, que a projeta mundo afora, cujas nações são detentoras de poder econômico e bélico, por outro também é preciso estar ciente de que se o "imperialismo linguístico", calcado pretensamente na figura do falante nativo, nos subjuga, ele pode ruir e já dá sinais nítidos disso, já que o inglês tem sido usado como língua franca; na prática mais por não nativos do que por nativos. Assim, se havia a missão de projetar a língua inglesa como mecanismo colonizador, é possível que apenas em parte isso tenha sido feito, por que, de fato, o inglês alcançou projeção sem precedentes. Mas acontece que muitas pessoas têm usado a língua inglesa, como uma espécie de reação transmoderna descolonial, ao manter as suas identidades, como se estivesse usando a arma do inimigo contra ele mesmo.

Ao compreendermos o status de língua franca global do inglês, estaremos prontos para capacitar os nossos alunos para negociar com a variabilidade de normas do inglês no mundo todo, para que eles também possam se apropriar e usar essa língua criativamente. Trata-se, a meu ver, de uma pedagogia mais apropriada para a aprendizagem do inglês, que possibilitará 
vir à torna outros sentimentos, não mais negativos. Para tanto é preciso disseminar a descentralização do falante nativo como forma de beneficiar novos aprendizes/falantes do inglês, para que possam usar esse idioma sem constrangimentos ou receios de qualquer sorte.

\section{REFERÊNCIAS}

ANJOS, F. A. Desestrangeirizar a língua inglesa: um esboço da política linguística. Cruz das Almas: EdUFRB, 2019.

BARCELOS, A. M. F. Finding my own voice and accent. 1995. Disponível em: https://old.hltmag.co.uk/jun08/sart03.rtf. Acesso em: 31 de agosto 2019.

BERNAT, E. Towards a pedagogy of empowerment: The case of 'impostor syndrome'. Elted, vol. 11, p. 1-8, 2009.

COGO, A. English as a lingua franca: concepts, use, and implications. ELT Journal. Vol. 66/1, p. 97-105, 2012.

CRYSTAL, D. English as a global language. USA: Cambridge University Press, 2a ed. 2012.

FAIRCLOUGH, N. Language and Power. England: Longman Group, 1998.

JENKINS, J. English as a lingua franca: attitude and identity. Oxford, UK: Oxford University Press, 2007.

JENKINS, J. English as a lingua franca: interpretations and attitudes. World Englishes, v. 28, p. 200-207, 2009.

JENKINS, J. English as a língua franca from the classroom to the classroom. ELT Journal, p. 486-494, 2012.

RAJAGOPALAN, K. Por uma linguística crítica. Linguagem, identidade e a questão ética. São Paulo: Parabola, 2003.

\section{Como citar este artigo:}

ANJOS, Flávius Almeida dos. Ensinar e aprender inglês e a descentralizaão do falante nativo. Rev. EntreLínguas, Araraquara, v. 5, n. 1, p. 57-62, jan./jun. 2019. E-ISSN: 24473529. DOI: 10.29051/el.v5i1.12603

Submetido em: 30/11/2018

Revisões requeridas: 26/02/2019

Aprovado em: 10/03/2019

Publicado em: 30/04/2019 